\title{
Repair Concepts as Design Constraints of a Stiffened Composite PRSEUS Panel
}

\author{
Adam Przekop ${ }^{1}$ \\ Analytical Services and Materials, Inc., Hampton, VA, 23666
}

\begin{abstract}
A design and analysis of a repair concept applicable to a stiffened thin-skin composite panel based on the Pultruded Rod Stitched Efficient Unitized Structure is presented. The concept is a bolted repair using metal components, so that it can easily be applied in the operational environment. The damage scenario considered is a midbay-to-midbay saw-cut with a severed stiffener, flange and skin. In a previous study several repair configurations were explored and their feasibility confirmed but refinement was needed. The present study revisits the problem under recently revised design requirements and broadens the suite of loading conditions considered. The repair assembly design is based on the critical tension loading condition and subsequently its robustness is verified for a pressure loading case. High fidelity modeling techniques such as mesh-independent definition of compliant fasteners, elastic-plastic material properties for metal parts and geometrically nonlinear solutions are utilized in the finite element analysis. The best repair design is introduced, its analysis results are presented and factors influencing the design are assessed and discussed.
\end{abstract}

\section{Nomenclature}
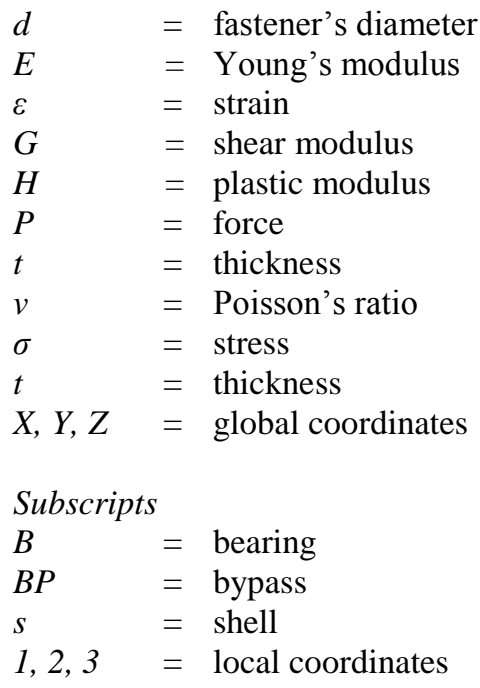

\section{Introduction}

$\mathrm{T}$ he primary structural concept being pursued as an important component of next generation airframe technology under the Environmentally Responsible Aviation (ERA) Program at NASA is the Pultruded Rod Stitched Efficient Unitized Structure (PRSEUS), ${ }^{1-8}$ illustrated in Figure 1. This concept is being developed in a partnership between NASA and The Boeing Company for application to future transport aircraft with the goal of developing lighter structure so that the aircraft will require less fuel and produce fewer pollutants. The PRSEUS structure is highly-integrated, weight-efficient, and has crack-arresting capabilities. In this concept a stitched carbon-epoxy material system is used. By stitching through the thickness of a dry material system, the labor associated with panel

\footnotetext{
1 Senior Structural Engineer, c/o NASA Langley Research Center, Hampton, VA 23681, Mail Stop 463,
} Senior Member AIAA. 
fabrication and assembly can be significantly reduced. When stitching through the thickness of pre-stacked skin, stringers and frames, the need for mechanical fasteners is almost eliminated. In addition, stitching reduces delamination and improves damage tolerance, allowing for a lighter structure with more gradual failures than traditional composites without through-the-thickness reinforcement. The PRSEUS concept consists of carbonepoxy panels fabricated from dry components and then infused in an oven while subjected to vacuum pressure. Skins, flanges and webs are composed of layers of carbon material forms that are pre-kitted in multi-ply stacks. A single stack contains seven plies $(+45,-45,0,90,0,-45,+45)$ where the 0 -degree plies are approximately twice the thickness of the \pm 45 and 90 -degree plies, resulting in a 0.052 in. stack thickness with percentage of the 0,45 and 90-degree fibers equal to $44.9,42.9$ and 12.2, respectively. Several stacks of the pre-kitted material are used to build up the desired thickness and configuration. As a naming convention, the 0 -degree stack orientation coincides with the orientation of the dominant 0 -degree plies. Stiffener flanges are stitched to the skin and no mechanical fasteners are used for joining. To maintain the panel geometry during fabrication, first stiffeners and then the skin are placed in a tool for stitching prior to moving the assembly to a curing tool for consolidation in the oven. The stiffeners running in the axial direction consist of webs with unidirectional carbon fiber rods at the top of the web. AS4 carbon fiber overwraps surround the rod. The stiffeners in the lateral direction are foam-filled hats. The manufacturing process is described in detail in ref. [6].

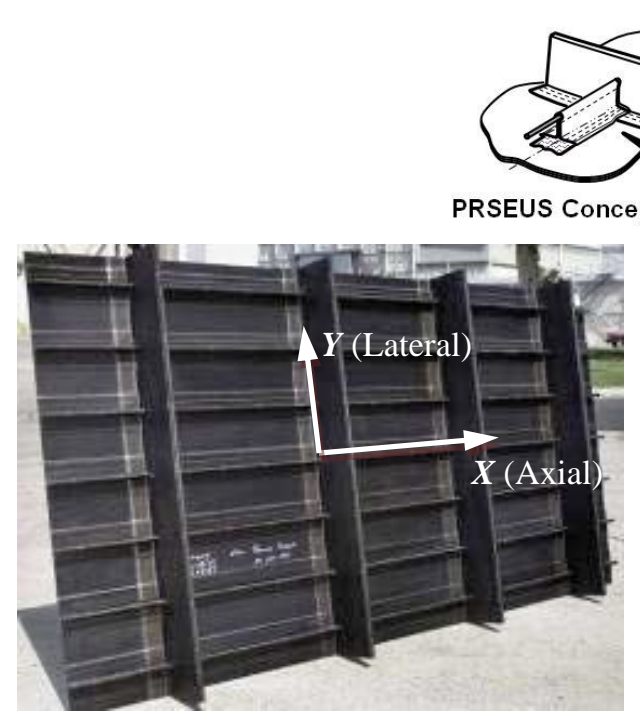

(a)

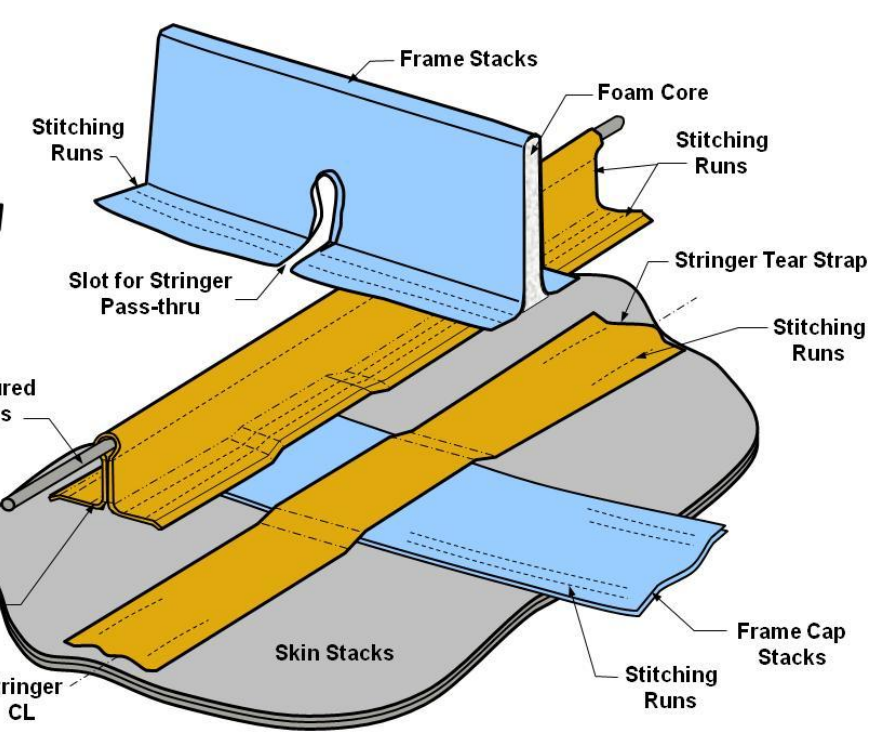

(b)

Figure 1. PRSEUS (a) sample flat panel and (b) general assembly concept. ${ }^{6}$

While providing several unique advantages, the PRSEUS concept also presents some inherent challenges not shared by conventional metallic airframes. ${ }^{9}$ Among these challenges are design concepts of manufacturing joints and repair techniques for rod-stiffened panels. While manufacturing joints and repair techniques should both be light-weight and meet ultimate load requirements, they are typically applied in different environments. While in a factory environment a large component with extensive damage might be replaced in its entirety, the replacement of a large highly-integrated component with localized damage is often cost-inefficient and impractical in the operational environment. In addition, composite technology-based repair such as bonding that requires a tightly controlled environment, perishable supplies, highly skilled workers and advanced tooling to produce a reliable bond may be acceptable in a factory environment but may not be in the field. Since from a practical standpoint, basic repairs cannot depend on the availability of a factory-like environment, repair techniques applicable to PRSEUS panels in an operational environment must be developed. This paper focuses on the development, design, and analysis of bolted repairs applicable to damaged PRSEUS panels. The proposed repair concept utilizes metallic fasteners rather than adhesive as the main load transfer mechanism.

Previous work ${ }^{10}$ focused on designing the repair for a tension loading condition. The present study revisits the problem with revised tension loading levels and also extends analysis to verify that a new design is applicable under other loading scenarios. While the design was verified for both compression and pressure loadings, only pressure and tension loadings are presented since these configurations are intended for experimental validation. The repair technique, designated as Mohawk, assumes aluminum alloy components and titanium alloy fasteners so that 
complications related to composite repair components are avoided. A severe damage to the PRSEUS panel, involving both the skin and rod-stringer (i.e., flange, web, and pultruded rod) is considered.

The remainder of the paper is organized as follows. Repair objective and its general concept are described first in section II. Next, a brief introduction of computational tools used in the effort and their previous validation is summarized in section III. The main activity focused on the repair of the tension panel is documented in section IV. This section is divided into three parts: subsection IV.A introduces the repair design, subsection IV.B describes its finite element (FE) modeling, and section IV.C presents obtained results and offers their critical assessment. Section $\mathrm{V}$ is dedicated to verification that a design dictated by the tension loading condition is robust enough so that it can be applied to PRSEUS panels under pressure loading. Since a different FE analysis code is used in this verification effort, subsection V.A highlights specifics of the FE pressure panel modeling and the results are presented in subsection V.B. Finally, concluding remarks are offered in section VI.

\section{Repair Objective and General Concept}

First and foremost, the repair assembly was required to restore the original load carrying capability of the pristine panel while incurring the smallest weight penalty possible. In general, while not formulated as a quantitative requirement, it was also desired that the mechanical behavior and load paths of the repaired panel resemble that of the pristine panel. Consequently, the repair design had to balance conflicting goals. On one hand, an excessively compliant repair assembly would probably lead to an insufficient load carrying capability of the repair parts and/or excessive loads transferred into the undamaged sections of the panel when compared to the pristine configuration under the same loading. On the other hand, a much stiffer repair assembly would lead to a larger than necessary weight penalty and significantly altered load paths underutilizing the undamaged sections of the panel. An exact stiffness match of the repair assembly to compensate for the simulated damage under multiple loading scenarios would likely produce a one-of-a-kind repair configuration that is complicated from a manufacturing standpoint. Such a configuration would likely involve features such as the dimensions of the crosssections of the repair parts continuously changing in the axial direction.

Based on previous experience, a tension loading was designated as a critical design condition. ${ }^{6,8}$ In addition, established design practices such as those regarding spacing requirements between metallic fasteners applied to a composite primary structure ${ }^{11}$ were followed. Finally, operational factors, e.g. what is practical in the environment that the repair technique was intended to be applied, also influenced the design.

The general Mohawk repair concept was first proposed by The Boeing Company and initial exploration was conducted in a proprietary study. The Mohawk concept incorporates previously outlined desired features and one of its early variations is presented in Figure 2. The repair consists of two aluminum alloy upper repair pieces whose bottom ends rest on the panel's top flange surface and the vertical portions are designed to accommodate the web with the pultruded rod. The two upper pieces are bolted directly together above the rod, and if advantageous, may also be bolted together through the stiffener web below the rod. The clearance between the two upper repair pieces and the pultruded rod ensures that the repair is not clamped on the rod. The lower ends of the repair components are bolted through the flanges to an aluminum alloy strap (not visible in Figure 2). The width of this lower strap is equal to or greater than the combined widths of the two upper repair pieces, as dictated by the extent of the damage being repaired. Note, that by incorporating a stiff pultruded rod offset from the panel surface, the pristine PRSEUS panels are designed to efficiently carry not only in-plane but also bending loads. Consequently, the Mohawk repair concept is designed such that the neutral bending axis of the three assembled repair pieces (the two upper pieces and the lower strap) coincides with the neutral bending axis of the pristine panel. This way Mohawk can transfer combined in-plane and bending loads in a similar fashion as the pristine panel.

From an airframe certification standpoint, ${ }^{12}$ metallic components must remain in the elastic regime up to the limit load. Above the limit load, a plastic regime is permitted if the metallic parts do not suffer or otherwise cause a catastrophic failure (the latter condition encompasses, e.g., jamming of control surfaces due to excessive plastic regime displacements, even though fracture does not occur). Although not stemming from regulations, an additional conservativeness was imposed on the repair in the current design process. Namely, that the repaired panel does not fail in the repair assembly before the panel itself suffers a failure in a location away from the repair. Therefore, an additional loading level was introduced to the repair design process. Apart from the limit loading (100\% of the design value) and the ultimate loading (e.g., $150 \%$ of the design value when mechanical tension loading is considered), a loading condition of the ultimate level plus $10 \%$ (i.e., $165 \%$ of the design tension loading) was added. Thus, the PRSEUS panel was required to withstand the ultimate loading, but the repair assembly was required to withstand the ultimate loading plus $10 \%$. 


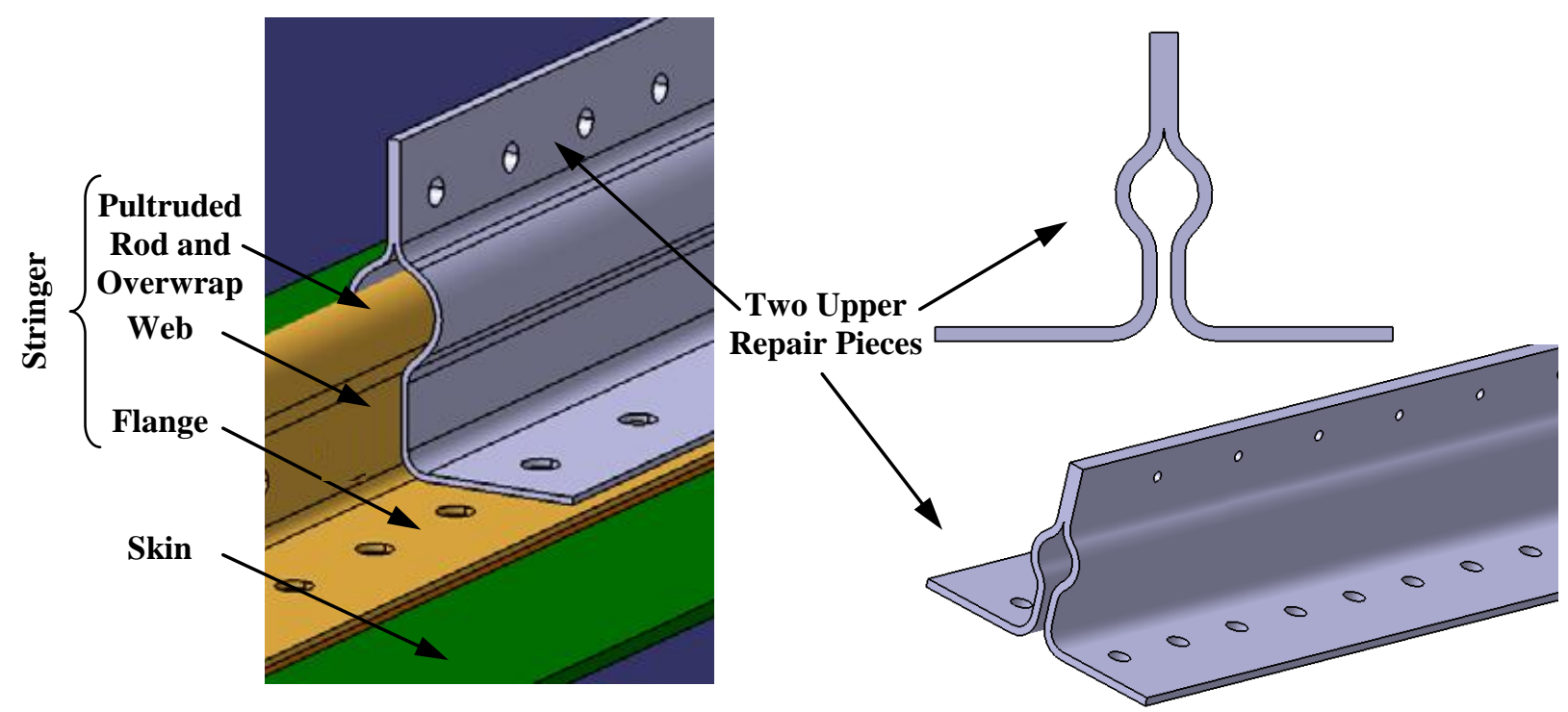

Figure 2. General Mohawk repair concept.

\section{Finite Element Analysis Tools and Their Validation}

Commercial FE packages Abaqus ${ }^{13}$ and Nastran $^{14}$ were used in the analyses being presented. The Abaqus/Standard (implicit) solver and Nastran Solution 106, both supporting material nonlinearity and geometrically nonlinear behavior were utilized. Use of two distinct FE packages originated mainly from the fact that the tension panel model was developed first using Abaqus in the course of the repair design activity. Pressure panel analysis was conducted after freezing the repair design, and to reduce FE model development effort, an existing Nastran model of the pristine pressure panel $^{7}$ was obtained and modified to a damaged and repaired configuration. In general, in the iterative process of arriving to the most efficient repair design, several FE model variations were developed in the course of the study based on the same methodology as described in the following section.

Validation of the analysis approach was conducted by analyzing single-stringer and three-stringer PRSEUS panels and comparing results obtained from the FE analyses with the corresponding available test data. Namely, the single-stringer panel was analyzed in a repaired configuration while the three-stringer panel was analyzed in a damaged but not repaired configuration. This validation was necessary to instill confidence in the methodology for predicting behavior of PRSEUS damaged structure and the Mohawk repair. The results of the FE validation effort are detailed in ref. [10].

\section{Tension Panel Repair}

A three-stringer dog-bone-shaped PRSEUS panel successfully tested by The Boeing Company in its NASA supported test effort ${ }^{8}$ to demonstrate the benefits of the across-thickness stitching in damage arrestment is presented in Figure 3. Data acquired in this tension test, at the loading range below which the existing saw-cut initiated further damage propagation was used in the FE modeling validation effort mentioned in section III. Use of the same panel and damage configuration was deemed consistent and beneficial for demonstration of the proposed repair concept. Furthermore, previous repair design and analysis work ${ }^{10}$ was also based on this configuration.

\section{A. Repair Design}

The PRSEUS tension panel with a saw-cut damage, as presented in Figure 3, was described in detail in refs. [6,8]. To recap briefly, the length of the test section of the panel between the foam-core frames was 20 in. and the spacing between rod-stringers was 6 in. The frame height measured from the outer (unstiffened) side of the panel was 6 in. and the foam used in the frame's core was 0.50 -in. thick. The total height of the stringer was $1.49 \mathrm{in}$. with the rod center offset of 1.25 in., both measured from the unstiffened side of the panel. The rod diameter was 0.375 in. The lamination stacking sequences of different sections of the panel are presented in Table 1 . The material properties of the panel and the repair assembly, details of which are yet to be introduced, are presented in Table 2. 


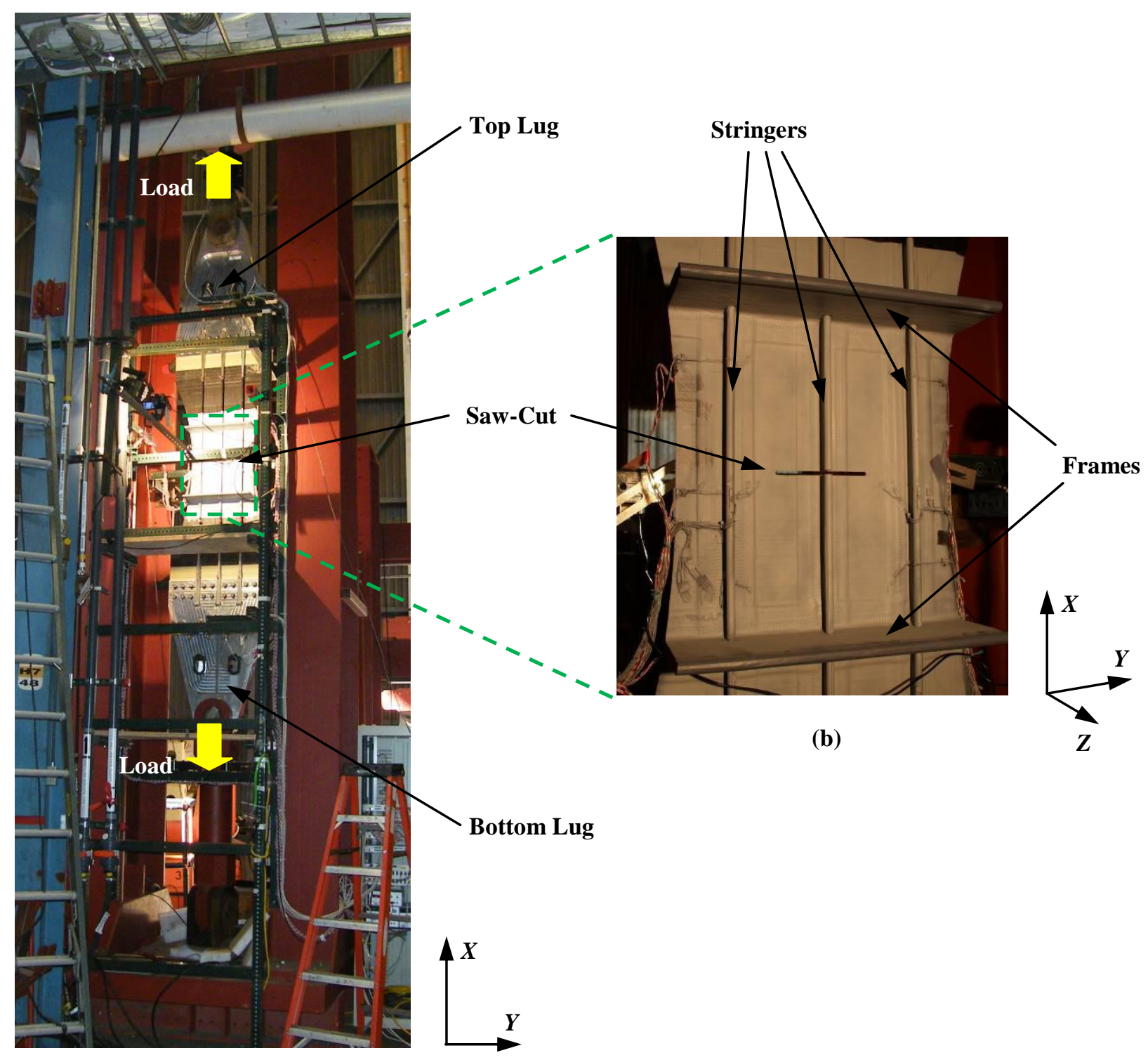

(a)

Figure 3. Three-stringer PRSEUS panel with saw-cut damage (a) test specimen in fixture, (b) test section close-up.

Table 1. PRSEUS panel lamination stacking sequence.

\begin{tabular}{cc}
\hline \hline Panel Component & $\begin{array}{c}\text { Stack Orientation } \\
\text { from the Unstiffened Side of the Panel, } \\
0^{\circ} \text { Along the } X \text {-Axis (Panel's Length) }\end{array}$ \\
\hline Skin & $(90)$ \\
\hline Skin w/Flange & $(90,0,0)$ \\
\hline Skin w/Frame Cap & $(90,90,90,90)$ \\
\hline Skin w/Flange and Frame Cap & $(90,90,0,0,90,90)$ \\
\hline Wrame & $(0,0)$ \\
\hline & $(0,0, \text { foam, } 0,0)^{*}$ \\
\hline American Institute of Aeronautics and Astronautics
\end{tabular}


Table 2. Material properties, room temperature., ${ }^{8,11}$

\begin{tabular}{|c|c|c|c|c|c|c|c|c|}
\hline \multirow[t]{2}{*}{ Material } & \multirow[t]{2}{*}{$\begin{array}{c}\mathrm{E}_{1}, \mathrm{Msi} \\
\left(\mathrm{H}_{1}, \mathrm{ksi}\right)\end{array}$} & \multirow[t]{2}{*}{$\begin{array}{c}\mathrm{E}_{2}, \mathrm{Msi} \\
\left(\mathrm{H}_{2}, \mathrm{ksi}\right)\end{array}$} & \multirow[t]{2}{*}{$v_{12}$} & \multirow[t]{2}{*}{$\mathrm{G}_{12}, \mathrm{Msi}$} & \multicolumn{2}{|c|}{$\begin{array}{c}\text { Tensile (Compression) } \\
\text { Strain Allowable } \\
\text { 1-direction, } \mu \text { in./in. }\end{array}$} & \multicolumn{2}{|c|}{$\begin{array}{c}\text { Tensile (Compression) } \\
\text { Stress Allowable, } \\
\text { 1-direction, ksi }\end{array}$} \\
\hline & & & & & Limit & Ultimate & Limit & Ultimate \\
\hline $\begin{array}{c}\text { Rod Toray } \\
\text { T800/3900-2B }\end{array}$ & 16.1 & & 0.30 & 6.19 & $\begin{array}{l}11,200 \\
(8,700)\end{array}$ & $\begin{array}{c}16,800 \\
(13,000)\end{array}$ & 260.0 & 390.0 \\
\hline $\begin{array}{c}\text { AS4-VRM34 } \\
\text { (Stack Properties) }\end{array}$ & 9.74 & 4.86 & 0.40 & 2.37 & $\begin{array}{c}7,000 \\
(5,800)\end{array}$ & $\begin{array}{l}10,500 \\
(8,700)\end{array}$ & 70.1 & 105.1 \\
\hline $\begin{array}{c}\text { Foam Core } \\
\text { Rohacell 110WF } \\
\end{array}$ & 0.021 & 0.021 & 0.32 & 0.008 & & & 0.294 & 0.441 \\
\hline $\begin{array}{c}\text { Aluminum Alloy } \\
\text { 7075-T6 }\end{array}$ & $\begin{array}{c}10.3 \\
(60.5)\end{array}$ & $\begin{array}{c}10.3 \\
(60.5)\end{array}$ & 0.33 & 3.87 & & & $\begin{array}{c}69.0 \\
(69.0)\end{array}$ & $\begin{array}{c}78.0 \\
(78.0)\end{array}$ \\
\hline $\begin{array}{c}\text { Titanium Alloy } \\
\text { Ti-6Al-4V Grade } 5\end{array}$ & 16.5 & 16.5 & 0.342 & 6.38 & & & $\begin{array}{c}128.0 \\
(128.0) \\
\end{array}$ & $\begin{array}{c}138.0 \\
(138.0)\end{array}$ \\
\hline
\end{tabular}

Loading levels considered for the tension panel were derived from a pristine panel assumed allowable average axial stress of $60 \mathrm{ksi}$ for the composite material system in the $-65^{\circ} \mathrm{F}$ environment. ${ }^{11}$ After multiplying the pristine cross-section area of the panel at its narrower width $\left(2.769 \mathrm{in}^{2}\right)$ by the allowable stress, the ultimate load of 166.1 kip was obtained at $-65^{\circ} \mathrm{F}$. Next, accounting for the environmental correction factor of 0.93 , i.e., effectively increasing the loading by a factor of $1 / 0.93=1.075$ to account for the analysis and upcoming validation testing being conducted in the room temperature rather than in $-65^{\circ} \mathrm{F}$, the ultimate load in the room temperature was determined to be 178.7 kip. Consequently, its value increased by $10 \%$, for the reasons discussed in section II, resulted in 195.5 kip. Finally, by dividing the ultimate loading by a factor of 1.5 , the limit loading of 119.1 kip was determined.

An exploded plot of the proposed repaired panel is presented in Figure 4. The panel was subjected to some preparation before installing the repair assembly. This preparation can be regarded as a part of the repair design, since it was intended to improve the way the repair assembly itself accepts and bears a desired portion of the panel's loading. The details of the panel prepared for installation of the repair assembly are shown in Figure 4. Panel preparation includes tapering the panel's center web and pultruded rod in the vicinity of the saw-cut damage. All the other sections of the panel remain unchanged with respect to the configuration used in the damage arresting demonstration test. The originally assumed simulated damage, i.e. 6-in. long and 1/4-in. wide midbay-to-midbay saw-cut, as seen in Figure 3b, remained unchanged only in the skin and flange sections of the panel. The web section, including the pultruded rod, is machined on both sides of the saw-cut such that the web is completely terminated above its bottom stitch line (refer to dashed lines in Figure 1b for locations of the stitch lines) over the span of $3.8 \mathrm{in}$. from the center, followed by 45 -degree taper extending to the bottom of the pultruded rod. The rod itself is further tapered at 15-degree angle, i.e. over the additional distance of approximately 1.4 in. While FE modeling discussion is reserved for section IV.B, two remarks helpful in understanding of Figure 4, which is based on the FE model, are warranted here. First, note that the rod taper would have a different shape in the actual repair but it was simplified to be axially symmetric in the FE model. Also note, that rod overwrap sections of the webs are not explicitly modeled as the beam elements rendered in red are visible.

The most efficient repair assembly design selected from several configurations analyzed within the course of the study is presented in Figure 4 as the grey-colored parts. Aluminum alloy 7075-T6 was used for all the inner- and outer-mold line (IML and OML) components of the repair assembly except titanium alloy Ti-6Al-4V fasteners. The thicknesses of the main sections of the machined repair assembly parts are labeled in red. General cross-section thicknesses of the repair parts were dictated primarily by ensuring that the yielding stress level is not exceeded at the limit loading and the ultimate strength is not exceeded at the ultimate loading $+10 \%$. Thinner OML strap ends were designed to reduce bearing stress peaking in the panel in the vicinity of the end fastener joints (to be discussed momentarily). In addition to this requirement, end sections of the IML repair pieces were tailored such that the PRSEUS panel IML thickness variations in the vicinity of the flange-frame cap intersections can be accommodated.

Fastener patterns used to install the repair assembly are shown in Figure 5a with the red squares. Locations of some of the fasteners installed in the IML repair pieces which are not visible in Figure 5a are presented in Figure 5b. Due to a smaller size of the IML pieces of the repair assembly in Figure 4, its more detailed representation is also offered in Figure 5b. Most of the fasteners used to install the repair assembly are 3/16-in. diameter lockbolts, unless otherwise noted in Figure 5. Specifically as shown in Figure 5a, to take advantage of the thicker flange-frame cap 
intersection of the panel (six stacks, 0.312 in.-thick) four 1/4-in. fasteners are used at the locations circled with a blue dashed line. Their increased stiffness permits larger load being transferred from the panel to the repair without exceeding allowable bearing stress levels in the composite. Note, that some of the effect of the increased fastener stiffness, and therefore higher loading, is compensated by the increased bearing area as the bearing stress

$$
\sigma_{B}=\frac{P_{B}}{t_{s} d}
$$

relates the bearing force $P_{B}$ to the bearing area calculated as a composite shell thickness $t_{s}$ multiplied by fastener diameter $d$. In contrast, to reduce the loading and, therefore, bearing stress peaks in the direct vicinity of the simulated damage, the four fasteners closest to the saw-cut are 5/32-in. diameter to make them more compliant. Opposite to the larger diameter fastener argument presented above, a portion of the bearing stress reduction originating from a reduced loading in a more compliant fastener is diminished by a reduced bearing area. The 5/32in. fasteners are also used above the PRSEUS panel stringers to attach together the two IML repair pieces. A smaller fastener diameter is selected for that location due to minimal loading that this row of fasteners is carrying. All 5/32-in. fastener locations are circled with a dashed black line in Figures 5a and 5b. Finally note, that fasteners seen in Figure 5a over the grey area of the IML repair assembly are double-shear fasteners as each penetrates the IML repair piece, PRSEUS panel and OML strap. All other fasteners are single shear fasteners as they penetrate only the PRSEUS panel and the OML strap, as seen in Figure 5a, or two IML repair pieces through the top row of fasteners, as seen in Figure 5b. A total of 129 fasteners is used in the repair, including 106 3/16-in., 19 5/32-in. and four 1/4-in. diameter fasteners. Per composite structure design guidelines, ${ }^{11}$ the fasteners are spaced no closer than the quadruple of their diameter apart, and no closer than triple of their diameter plus 0.06 in. from any free edge, e.g., from the saw-cut damage.

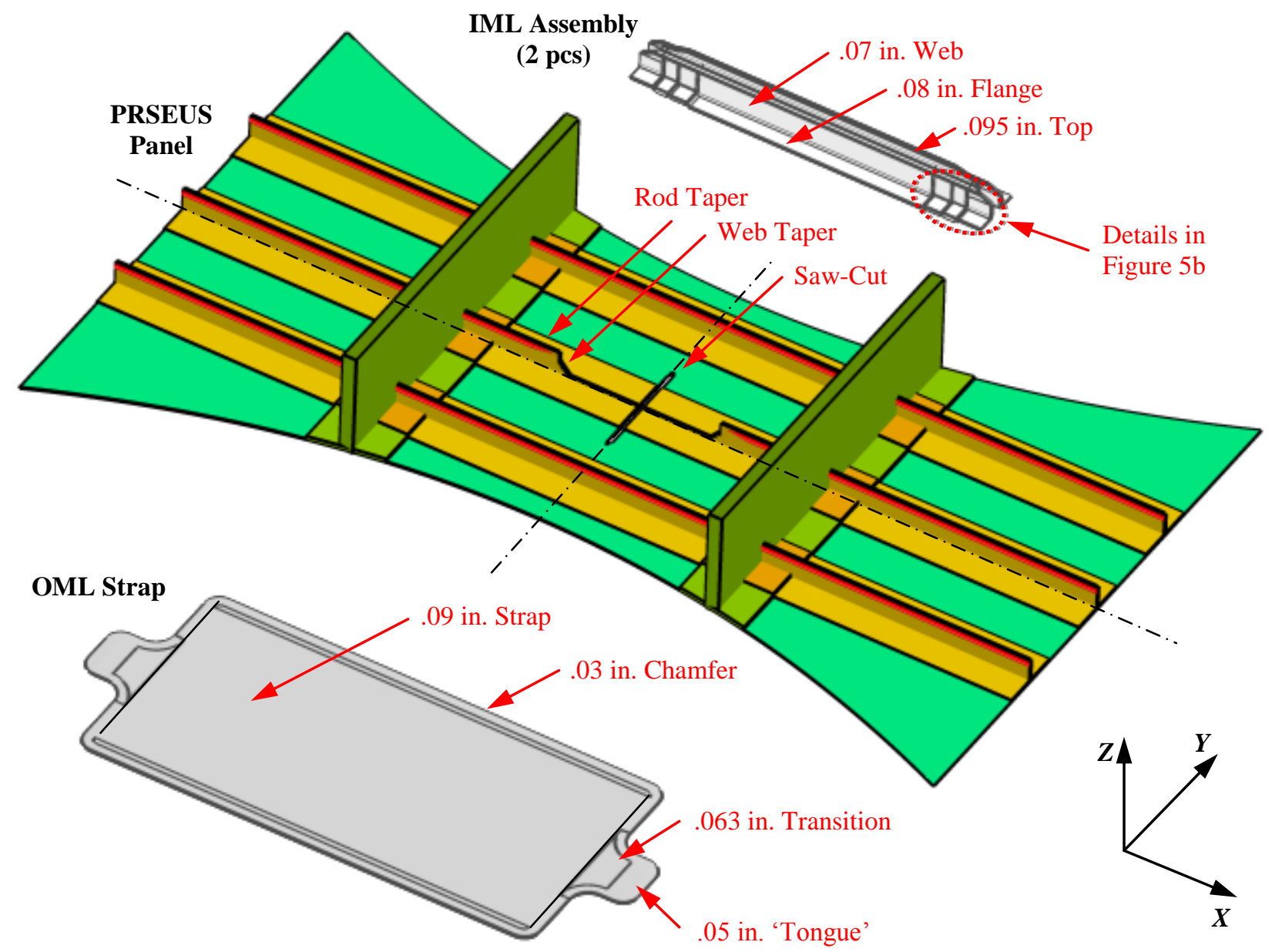

Figure 4. Exploded view of the saw-cut tension PRSEUS panel with Mohawk-type repair. 


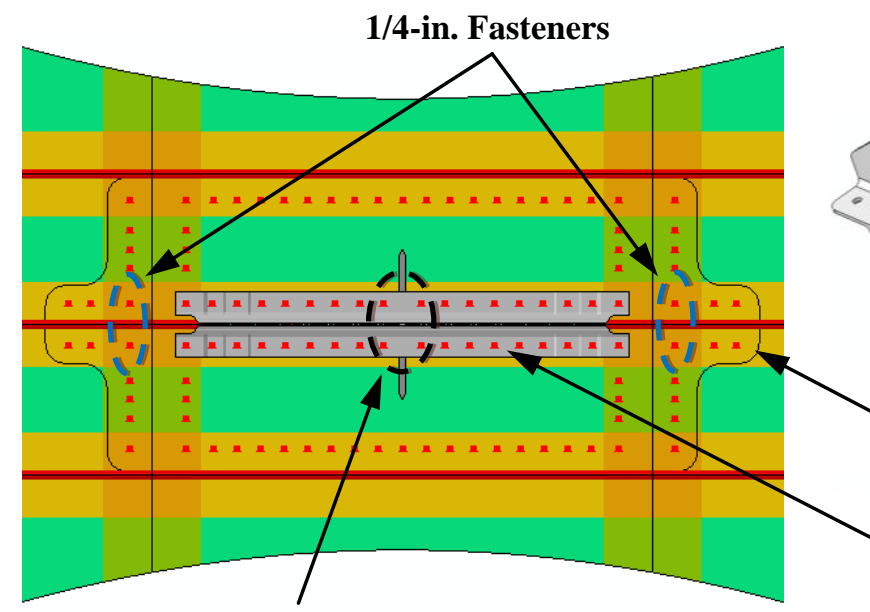

5/32-in. Fasteners

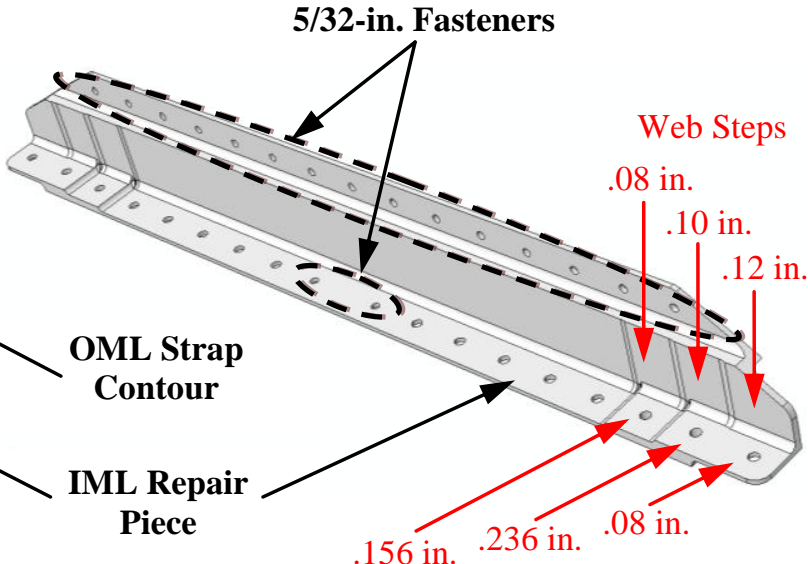

Flange Steps

(a)

(b)

Figure 5. Location of fasteners (a) top view, including IML assembly and OML strap contour with 1/4-in. and 5/32-in. fasteners circled, (b) IML piece with fastener holes and 5/32-in. fasteners circled.

\section{B. Finite Element Modeling}

The Abaqus FE model of the PRSEUS panel was discretized using four-node S4R5 shell elements for all of its components except the pultruded rods which were modeled using two-node B31 beam elements. The section of the web overwrapping pultruded rods was not explicitly modeled. Instead, the entire web was modeled as a planar surface and one line of shell element edges and beam elements were collocated sharing the same subset of nodes. The repair assembly parts were also discretized using primarily S4R5 shell elements and few three-node S3 elements. A typical element edge length was approximately 0.2 in. Holes to accommodate fasteners were not modeled per customary global modeling practices. ${ }^{11,13,14}$ Fasteners were modeled using two-node CONN3D2 connector elements with their stiffness components computed externally using the Huth Hi-Lok formulation available in Nastran ${ }^{14}$ and assigned to afore-mentioned connector element property definitions. Note, that in Abaqus automated fastener stiffness computation is not available, so the above step was undertaken to make tension and pressure panel modeling as consistent as possible. Furthermore, note that a single fastener element models a connection between two surfaces, and consequently suffices to model a single-shear fastener. When one fastener joins together three surfaces, i.e., acts as a double-shear fastener, two connector elements defined in series are needed. Therefore, to model the total of 129 fasteners, 36 of which are double shear fasteners as illustrated in Figure 5, the total number of required connector elements is 165 .

Per aircraft certification requirements in the transport category ${ }^{12}$ cited in section II, a metallic structure is expected to remain in the elastic regime below the limit load, but the plastic regime is permitted at loads greater than the limit load. Consequently, aluminum alloy elastic-plastic material properties, modeled as a bi-linear stress-strain relationship, were utilized in the Mohawk repair assembly. All composite material properties were modeled as elastic only. Titanium alloy fasteners were not permitted to exceed their yield stress values, so they were also assigned only elastic material properties.

As presented in Figure 4, only the 50-in. center section of the repaired panel, away from the installation lugs was modeled, as the original pristine panel was designed to produce a uniform in-plane displacement across the panel width at the ends of this section. Consequently, force distribution across the panel width at its end stations could not be known a priori. Thus, by constraining one end of the repaired panel and applying a uniform in-plane displacement at the other end, and interrogating the resultant reaction force at the boundary, the desired enforced inplane displacements were determined in the iterative fashion. For the three prescribed loadings levels of $119.1 \mathrm{kip}$, $178.7 \mathrm{kip}$ and $196.5 \mathrm{kip}$ discussed before, the corresponding uniform in-plane displacements of $0.2042 \mathrm{in}$., 0.3048 in. and 0.3353 in. were found, respectively. 


\section{Results and Critical Design Assessment}

Results obtained at the limit loading level of 119.1 kip are illustrated in Figure 6 through Figure 9. In-plane displacement field in the direction of the loading (i.e., the $\mathrm{X}$-axis direction) for the entire repaired panel is presented in Figure 6. It is seen that a smooth and uniform displacement across-the-width of the panel (i.e., in the Y-axis direction) was obtained in the section between the frames and no excessive disruption of the displacement field occurs due to the presence of the repair assembly. Maximum axial strain in the panel is presented in Figure 7 where the repair assembly is not plotted. The color bar legend in this plot is terminated at the stack 0 -degree tension limit allowable strain of $7000 \mu \varepsilon,{ }^{8}$ therefore all the locations exceeding this value are plotted in grey. It is seen that only small areas in the vicinity of the frame cap edges and at the tips of the saw-cut (as indicated) exceed the allowable strain value. However, in both cases the global FE model lacks enough fidelity to accurately compute local strain levels and tends to overestimate them. In the actual panel a more gradual cross section change exists where, e.g., a single-stack skin (0.052 in. thickness) transitions into a four-stack frame cap (0.208 in. thickness) while in a FE model a step change of the cross section is effectively introduced. The skin-toframe cap transition area was the subject of a separate proprietary study using refined local analysis utilizing StressCheck software ${ }^{15}$ and concluded that this area should not yield critical strain values. Also an array of testing conducted thus $\mathrm{far}^{6-8}$ supports this conclusion. Similarly, a typical 0.2 -in. element size used in the global FE model is insufficient to accurately represent a 0.125 -in. radius at the saw-cut tip. Furthermore, while stop-drills may be introduced to mitigate strain concentration at the saw-cut tips, ${ }^{10}$ this step is likely not required, as some design manuals, e.g., ref. [11], recommend verifying allowable values at certain distances (called characteristic lengths) away from the cut-out edges due to the presence of the stress relief in composites. Due to proprietary nature of ref. [11] the specific characteristic length value is not cited here.

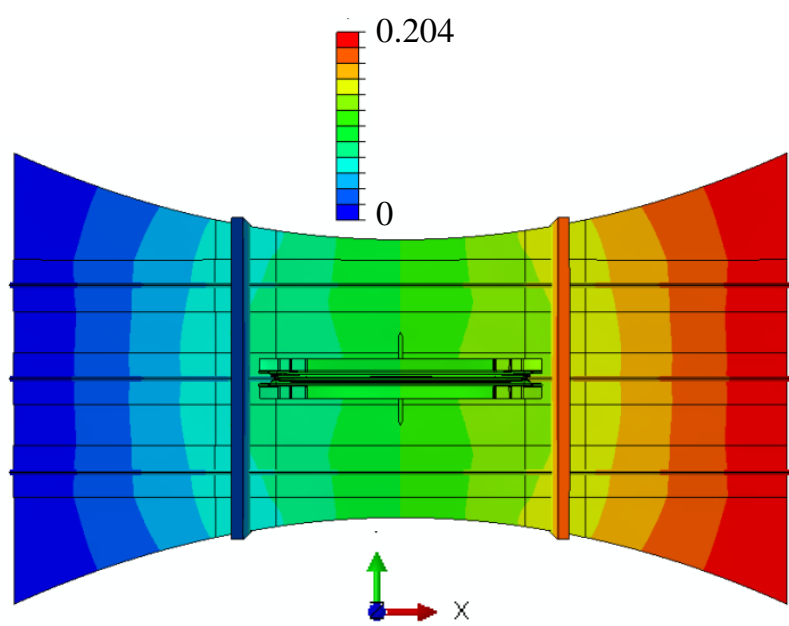

Figure 6. In-plane (X-axis) displacement (in.) at limit loading of 119.1 kip.

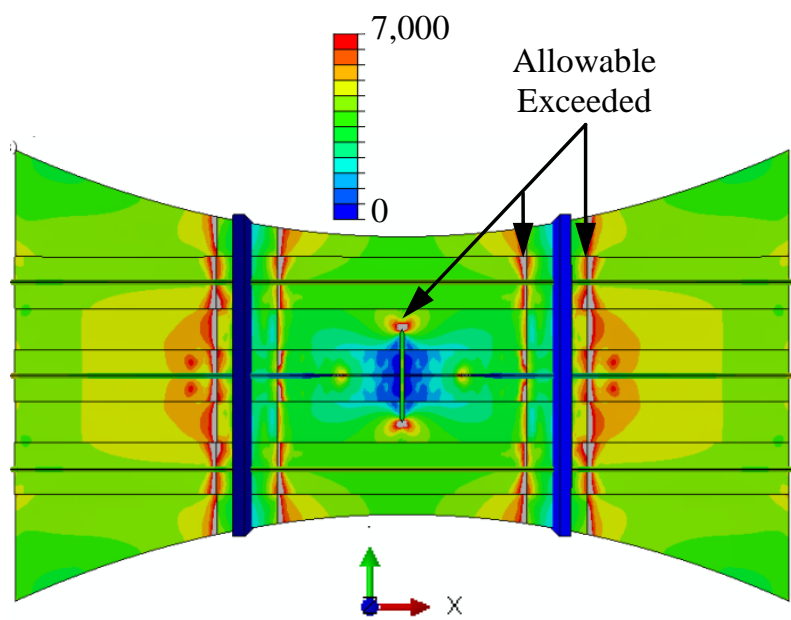

Figure 7. Maximum axial strain $(\mu \varepsilon)$ at limit loading of 119.1 kip.

Maximum principal stress fields in the OML repair strap and the IML assembly are presented in Figure 8 and Figure 9, respectively. It is seen that the repair assembly does not exceed the allowable yielding stress level of $69 \mathrm{ksi}$. The maximum stress levels in the OML strap are found to be $50.5 \mathrm{ksi}$ and are located in the 'tongue' areas of the strap near the fastener joints. The maximum stress levels in the IML assembly are higher, reaching $63.3 \mathrm{ksi}$, and occur at the ends of the IML repair pieces in the fillets between the flange and web sections of the repair. Note, that the design of this section of the IML assembly exemplifies a compromise between the two conflicting factors inherent to this repair design. On one hand, increased thickness of the end sections of the IML repair piece allows distribution of a load over an increased cross section area, and therefore may reduce stress levels. At the same time, increased thickness means increased stiffness and results in higher loads being transferred into the IML assembly from the damaged panel. Consequently, passed certain thickness value, stress level reduction may be diminished or even not achievable. This in turn, not only adversely affects the repair assembly itself, but also may lead to undesirably high fastener loads and/or fastener-generated bearing stress levels in the composite holes accommodating these fasteners. Furthermore, over-stiff repair assembly alters the overall load paths in the repaired panel, potentially making them very different from those of the pristine panel. 


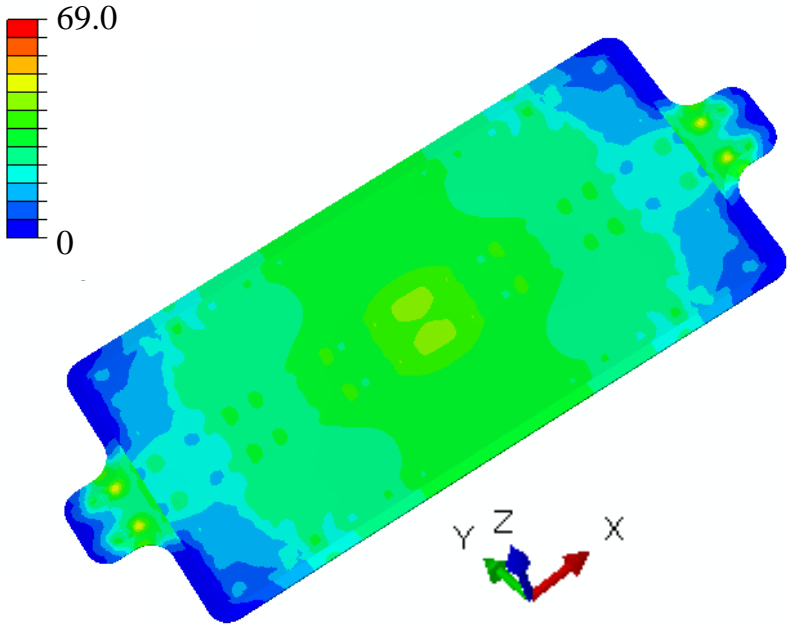

Figure 8. OML strap maximum principal stress (ksi) at limit loading of 119.1 kip.

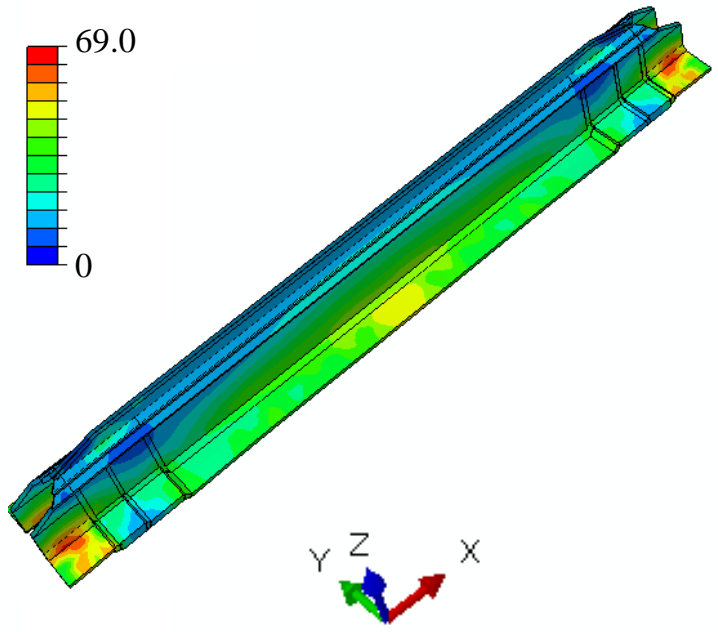

Figure 9. IML repair assembly maximum principal stress (ksi) at limit loading of 119.1 kip.

Results obtained at the ultimate loading level (178.7 kip) for the panel and the ultimate loading $+10 \%$ level (196.5 kip) for the repair assembly are illustrated in Figure 10 through Figure 15. The in-plane displacement field for the entire repaired panel is presented in Figure 10. Similar to in-plane displacement field obtained for the limit load level presented in Figure 6, a smooth and uniform panel displacement field across-the-width was obtained in the section between the frames. Maximum axial strain in the panel is presented in Figure 11 where again, the repair assembly is not plotted. The color bar legend in this plot is terminated at the stack 0-degree tension ultimate allowable strain of $10,500 \mu \varepsilon$, therefore all the locations exceeding this value are plotted in grey. Again, similar to the results presented before in Figure 7, it is seen that only small areas in the vicinity of the frame cap edges and at the tips of the saw-cut are exceeding allowable values. Per argument presented before when discussing Figure 7, strain levels in these areas are judged to be likely overestimated, and should not cause a premature failure of the panel.

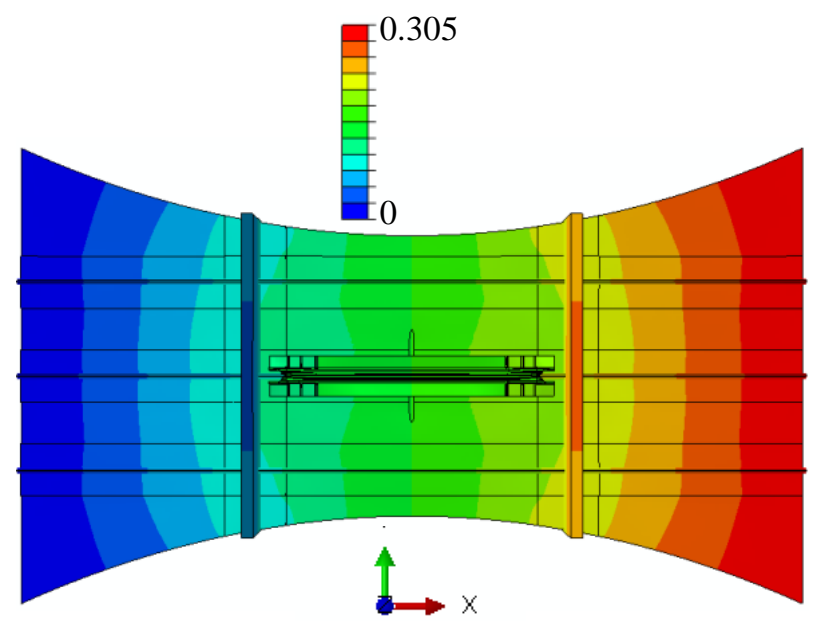

Figure 10. In-plane (X-axis) displacement (in.) at ultimate loading of 178.7 kip.

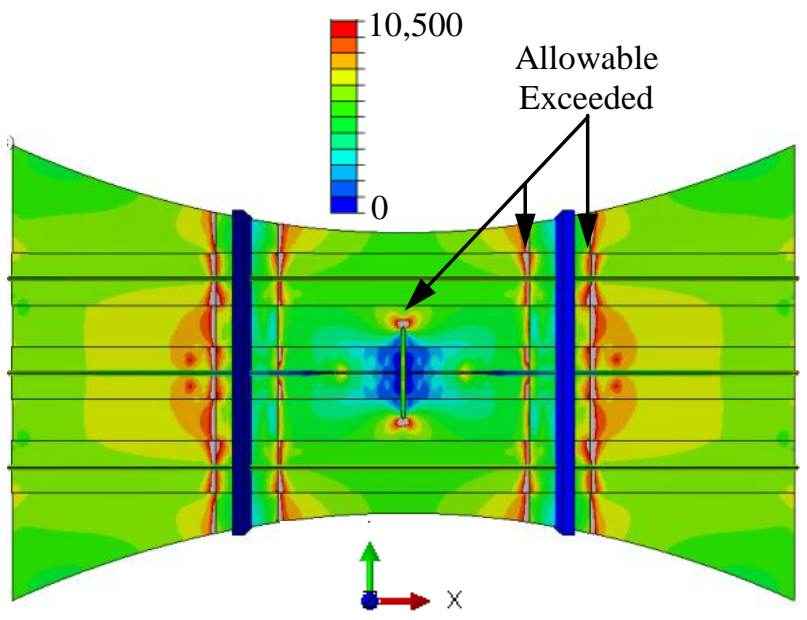

Figure 11. Maximum axial strain $(\mu \varepsilon)$ at ultimate loading of 178.7 kip.

Maximum principal stress fields in the OML repair strap and the IML assembly are presented in Figure 12 and Figure 13, respectively. It is seen that the repair assembly does not exceed the allowable tensile strength level of $78 \mathrm{ksi}$. Maximum stress levels in the OML strap are found to be $74.7 \mathrm{ksi}$ and are located in the 'tongue' areas of the strap in the vicinity of the second row of fasteners. The maximum stress levels in the IML assembly are higher, reaching $77.3 \mathrm{ksi}$, and occur at the ends of the IML repair pieces in the fillets between the flange and web sections of the repair. For both OML and IML repair pieces, the maximum stress levels at the ultimate loading $+10 \%$ coincide 
with the corresponding locations identified for the limit loading condition. Note, that the red areas are indicative of a plastic response regime, i.e., when stress level exceeds the yielding stress of $69 \mathrm{ksi}$. It is seen that apart from the locations discussed before when identifying the highest stress level locations, plastic response regime is also present in both OML and IML repair pieces in the vicinity of the saw-cut damage, i.e., at the mid-span of the OML strap and the mid-span of the IML repair assembly. Overall, the plastic response regime is an important factor when localized highly-stress sections of the repair assembly are of interest. Specifically, a plastic response results in stress relaxation, absence of which would otherwise result in significantly overestimated stress levels in the localized areas where the yielding stress is exceeded. Since these areas, however, are limited to relatively small sections of the overall repair assembly, their impact on the global response is minimal. When the in-plane force versus in-plane displacement plot was produced, the relationship (not shown here for brevity) exhibited virtually linear dependency. The above observation also points to the fact that no significant geometric nonlinearity was present in the analysis. Considering application of the inplane loading only and the fact that the neutral bending axis of the repair assembly coincided with the neutral bending axis of the pristine panel, this result comes as no surprise.

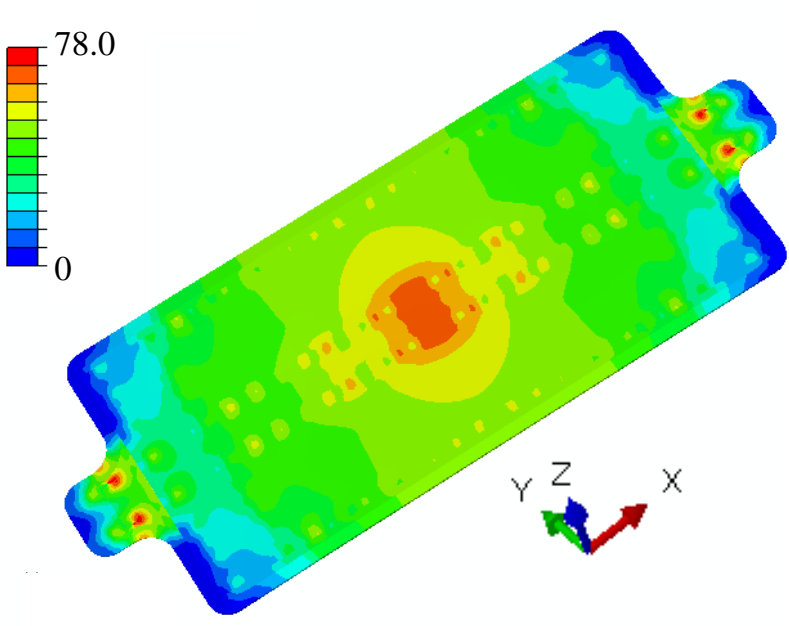

Figure 12. OML strap maximum principal stress (ksi) at ultimate loading $+10 \%$ of 196.5 kip.

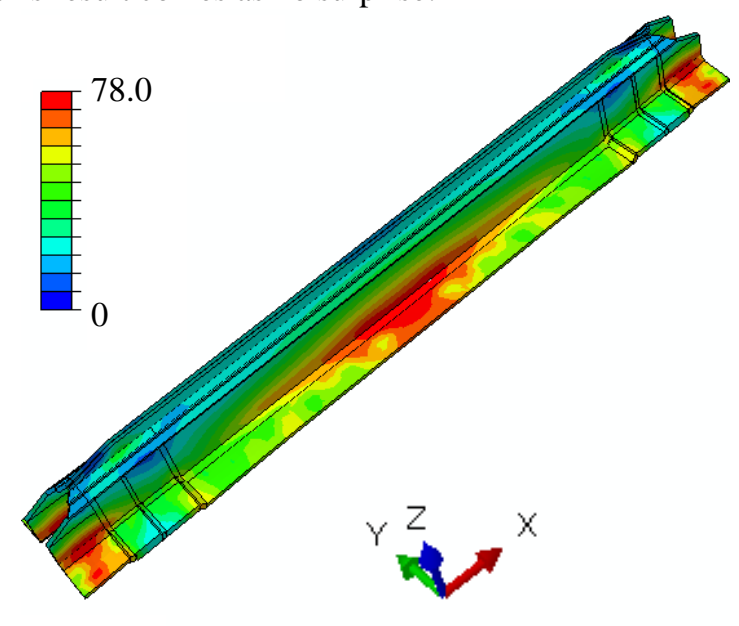

Figure 13. IML repair assembly maximum principal stress (ksi) at ultimate loading $+\mathbf{1 0 \%}$ of 196.5 kip.

The center flange was found to be the critical location when the bearing stress and bypass strain levels were considered. Bearing stress and bypass strain distributions along the length of the panel's center flange at the ultimate loading level $+10 \%$ (196.5 kip) are presented in Figure 14. Note, that due to symmetry about the axial and lateral direction (as depicted with dash-dotted lines in Figure 4), distributions on both sides of the center stringer and both sides of the saw-cut are also symmetric. In Figure 14 span station of -10 in. corresponds to the location of the center of the left frame, and 0 in. span station to the center of the saw-cut. Vertical black dashed lines highlight the width of the frame cap and the edge of the saw-cut damage, as annotated. Bearing stresses are computed per Eq. (1) from the fastener force output, while the bypass strains are directly available from the FE analysis, e.g., as presented in Figure 11. Note however, that Figure 11 was obtained at the ultimate load level, and consequently as mentioned before, it is intended for evaluation of the panel away from the fastener attachments. The strain results used in Figure 14 are obtained at the ultimate level $+10 \%$ as they are intended for the repair assembly evaluation.

The highest value of the bearing stress is reached at the row of fasteners closest to the saw-cut, as seen in Figure 14, even though the diameter of these fasteners was reduced from 3/16-in. used elsewhere to 5/32-in. to reduce their stiffness. Other locations where the bearing stress levels are also high include the first row of fasteners at the end of the OML 'tongue,' which is a typical peaking effect associated with a doubler termination. Similar effect is also seen in the fourth and fifth rows of fasteners from the left, which are the first two rows of fasteners that attach the IML assembly (the first three fasteners from the left attach the OML strap only). The effect is stretched over the two consecutive fastener rows because the IML repair pieces have variable thickness in this region and, therefore, resemble a staggered two-step termination. Note, that when the third row of fasteners is excluded from the discussion, the overall variation of the bearing stress ranges from approximately 60 to $100 \mathrm{ksi}$. While the ideal distribution would be constant, such a design is not practical to be defined and manufactured. The presented design is a compromise between simplicity and a desired bearing stress distribution. It needs to be underscored, that the 
bearing stress distribution was significantly enhanced by the center web and pultruded rod tapers described before in section IV.A. These features were specifically tailored to flatten the bearing stress distribution by promoting early transfer of the loading from the stringer into the repair assembly, before the saw-cut stringer termination is reached. Also note, that the afore-mentioned third row of fasteners from the left, which produces the lowest bearing stress values, has a limited ability to be re-designed more efficiently to transfer higher load levels. Recall from section IV.A, that this fastener has already a larger diameter of $1 / 4 \mathrm{in}$. which, due to spacing limitations, cannot be further increased.

The bypass strain distribution presented in Figure 14 displays a gradual, almost monotonic decay from its peak value at the beginning of the OML strap 'tongue' to its lowest value in the vicinity of the saw-cut. Such a distribution is expected, since away from the saw-cut, all three stringers are expected to carry approximately the same loading. As the saw-cut is approached, the loads from the center stringer are gradually transferred through the fasteners into the repair assembly. In the limit, i.e., on the edge of the saw-cut, bypass strain should asymptote to zero, as the center flange is unable to support any $\mathrm{X}$-axis load component at this location.

The bearing stress versus bypass strain envelope is presented in Figure 15. While it presents the same data as Figure 14, and the spatial distribution information is lost, it is an important format for a bolted joint result representation as the allowable values of bearing stress and bypass strain are not independent. While the allowable envelope cannot be plotted in Figure 15 due to its proprietary nature, ${ }^{11}$ a minimum required envelope encompassing the results of the FE analysis is plotted with a red dashed line. Annotated in Figure 15 are points that are critical in the current design or may become critical in a further effort to tune the design. As indicated before, the point labeled as 'saw-cut vicinity fastener' was already subject to refinement of the fastener diameter to reduce its bearing stress value. Therefore, any further reduction in the bearing stress level there is judged difficult. On the other hand, the other two highlighted points are associated with the OML strap 'tongue' and improvement in this section of the repair assembly is deemed more plausible. Specifically, elimination of the 'tongues' can be considered leaving the OML strap as a rectangular contour with rounded corners. In the most desirable scenario it may yield a reduction in the envelope that approaches the green dashed line in Figure 15. Certainly, the bearing stress and bypass strain levels are not independent of each other along the flange span. Examination of Figure 14 and Figure 15, however, seem to hint that the most substantial bearing stress increase when the 'tongues' are eliminated should result at the third fastener from the left. This fastener, however, is none of those that span the green dashed-line envelope, so even a significant movement of this data point in Figure 15 can still be accommodated within the boundaries of the desired shrunk envelope.

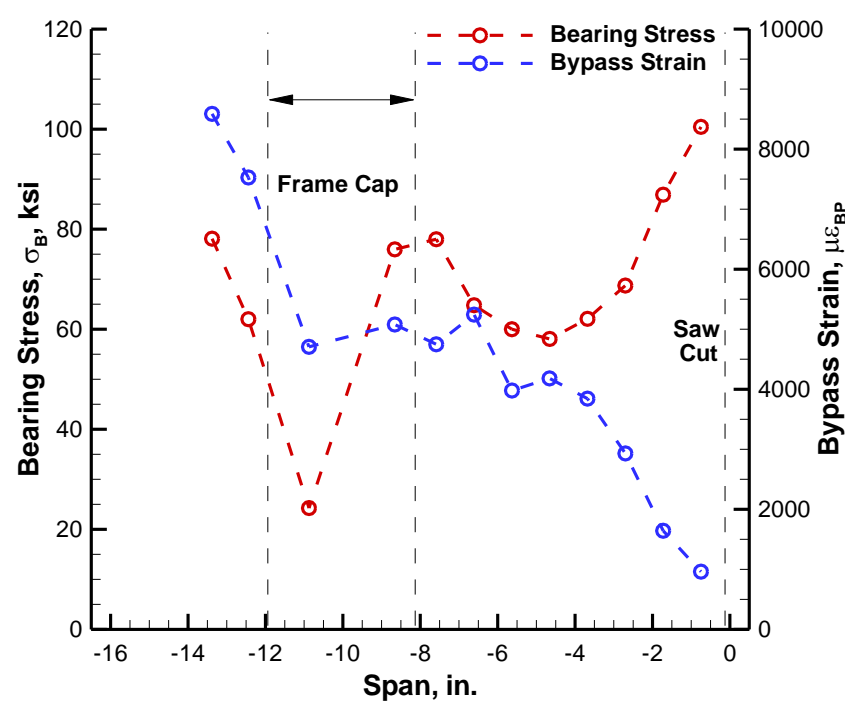

Figure 14. Center flange spanwise bearing stress and bypass strain distributions at ultimate loading $+10 \%$ of 196.5 kip.

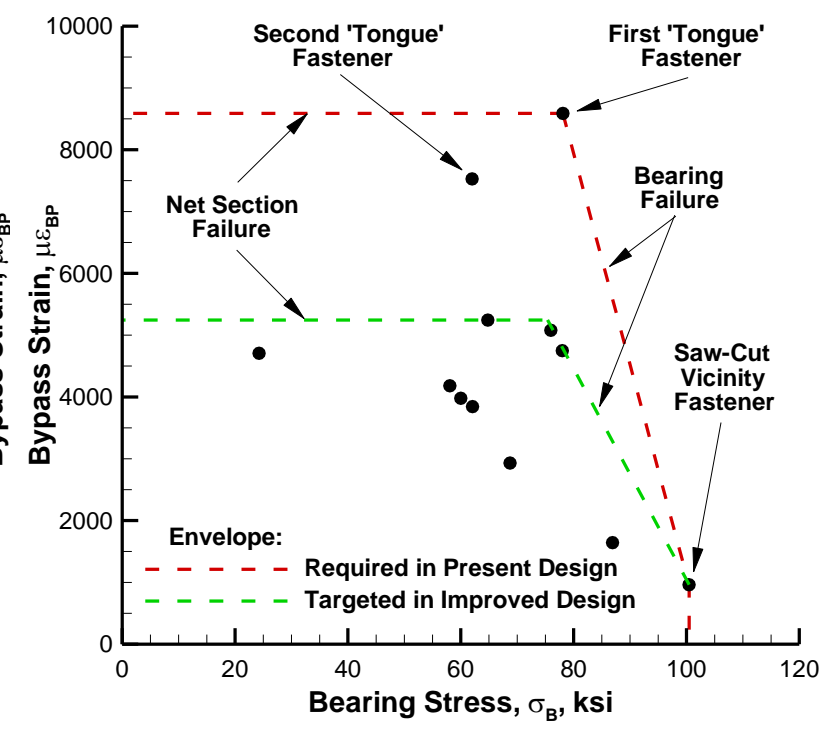

Figure 15. Center flange bearing stress versus bypass strain envelope at ultimate loading $+10 \%$ of 196.5 kip.

In conclusion, the presented repair configuration satisfies all the material allowables, design requirements, guidelines, and objectives. Introduction of some minor modifications enhancing the safety margins of the current design may, however, still be possible. 


\section{Pressure Panel Repair}

Following successful development of a metallic repair applicable to the PRSEUS tension panel, its suitability to repair a pressurized PRSEUS panel was evaluated. Since a robust repair concept applicable across a range of distinct loading conditions was sought, no effort was made to modify the repair designed for the tension panel, and it was applied 'as is' to the pressure panel with the same saw-cut damage.

Similar to the tension panel effort, an existing pressure panel test article configuration ${ }^{7}$ was adopted in the studies. The overall test set up of a recent pristine pressure panel test ${ }^{7}$ is presented in Figure 16. The coordinate system presented in Figure 16 is consistent with the one presented in Figure 1a and throughout the tension panel discussion in that sense that stringers are oriented along the $\mathrm{X}$-axis and frames along the $\mathrm{Y}$-axis. Since the pressure panel is mounted on the pressure vessel such that the panel substructure faces to the inside of the pressure vessel, the Z-axis is oriented to the outside of the pressure vessel, i.e., an elevated pressure inside the vessel causes a positive out-of-plane panel deformation. The dimensions of the opening at the top of the pressure vessel to which the panel was mounted were 100 in. by 40 in. and can be regarded as equal to the test section dimensions of the pressure panel. The substructure of the panel comprised of 15 stringers spaced 6 in. apart and two frames spaced 20 in. apart, i.e., the same substructure spacing as for the tension panel was maintained. Also unchanged, when compared with the tension panel, were the lamination stacking sequences and material properties, as introduced before in Table 1 and Table 2, respectively. Note that unlike the tension panel, the pressure panel longer direction is aligned with frames rather than stringers.

The 6 in. by 1/4 in. midbay-to-midbay saw-cut damage was modeled as in the tension panel, i.e., in the middle of the center stringer which is the eighth stringer counting from either edge of the panel. The same panel preparation for the repair assembly installation as for the tension panel was assumed, i.e., the web and pultruded rod tapers were introduced as illustrated in Figure 4. Also unchanged were the locations and sizing of all the fasteners attaching the repair assembly, as illustrated in Figure 5.

\section{A. Finite Element Modeling}

As indicated before, an existing Nastran FE model of the pressure panel used in its pristine configuration studies ${ }^{7}$ was made available and, to expedite FE analysis development, served as a precursor for developing the repaired panel model. By analogy to the previously detailed Abaqus model, four-node and three-node shell elements CQUAD4 and CTRIA3 were used instead Abaqus S4R5 and S3 elements, respectively. Similarly, beam elements CBAR were used instead of B31 and the same approach neglecting explicit modeling of the pultruded rod overwraps was applied to stringers. A typical element size for the PRSEUS panel was approximately 0.25 in. and the discretization of the repair assembly matched exactly the one of the tension panel. Abaqus two-node CONN3D2 connector elements were substituted with Nastran CFAST elements with Huth Hi-Lok stiffness evaluation procedure. The same CFAST connector elements were utilized not only for the repair assembly attachment to the panel, but also to model installation of the entire panel to the pressure vessel along its perimeter. The pressure vessel was also modeled with shell elements but with much coarser discretization when compared to the PRSEUS panel and the repair assembly. While the repair was intended to restore pressurization capability of the panel, the sealant that is typically used to achieve this objective was not modeled, as it was not intended to carry any appreciable mechanical loadings.

The loading level selection to be considered in the pressure panel analyses followed the logic applied for the tension panel load selection. Therefore, apart from the limit and ultimate loadings, also the ultimate loading $+10 \%$ level was considered. Pressure loadings are typically selected based on the cruise flight level certification objectives. For the PRSEUS panel the following values were set: limit loading of $9.2 \mathrm{psi}$, ultimate loading of $18.4 \mathrm{psi}$ and ultimate loading $+10 \%$ of $20.24 \mathrm{psi}$. The first two values matched exactly the levels used in the pristine panel testing. ${ }^{7}$ Note, that for pressure loadings it is customary to designate double of the limit load as the ultimate load, while for tension loadings the ratio between the two loading levels is typically 1.5 .

\section{B. Results}

A solution was first obtained at the limit load level of 9.2 psi but for brevity these results are not presented, as all the obtained strain and stress levels were judged insignificant when compared with their corresponding allowables.

Results obtained at the ultimate loading level of 18.4 psi are illustrated in Figure 17 through Figure 19. The outof-plane displacement field for the entire repaired panel is presented in Figure 17, where the location of the OML repair strap and the contour of the saw-cut damage are identified. It is seen that a smooth displacement field was obtained and no excessive disruption of the displacement field occurs due to the presence of the repair assembly. Small displacement variations corresponding to substructure spacing are visible (so called 'pillowing') and a slight 
suppression of the out-of-plane displacement within the area coved by the OML strap is also noticeable. Consequently, the maximum out-of-plane displacement of $0.586 \mathrm{in}$. occurs to the side of the OML strap while for the pristine panel $^{7}$ the maximum out-of-plane displacement occurred in the area now covered with the OML strap and had a slightly higher value of 0.608 in. $^{7}$ It is worth mentioning that while no significant geometrically nonlinear behavior was noted for the tension panel, a stiffening nonlinearity was indentified under the pressure loading. This nonlinearity was expected since pressure loading acting on a thin-walled structure typically has a potential for producing out-of-plane displacements that are large enough to cause appreciable in-plane stretching, which in turn tends to suppress the out-of-plane deformation. For the maximum loading level considered (i.e., the ultimate loading $+10 \%$ of 20.24 psi) and after verifying that no plastic response regime was present, a linear solution (Nastran solution 101) yielded the maximum out-of-plane displacement of 0.734 in, whereas the nonlinear solution (Nastran solution 106, used throughout the repaired pressure panel analysis) resulted in the maximum displacement of 0.639 in. Thus, the linear out-of-plane displacement solution was overestimated by $14.9 \%$. Note, that for the pristine panel under $18.4 \mathrm{psi}$ loading, the linear and nonlinear maximum out-of-plane displacements were found to be 0.666 in. and 0.608 in., respectively. ${ }^{7}$ Thus, the linear out-of-plane displacement solution was overestimated by $9.5 \%$. Considering a slightly different loading levels and locations of the maximum out-of-plane displacement, the effect of nonlinearity can be regarded as comparable for the pristine and repaired panels. Finally, as expected, when inspecting the displacement results no appreciable deformation of the pressure vessel was noted.

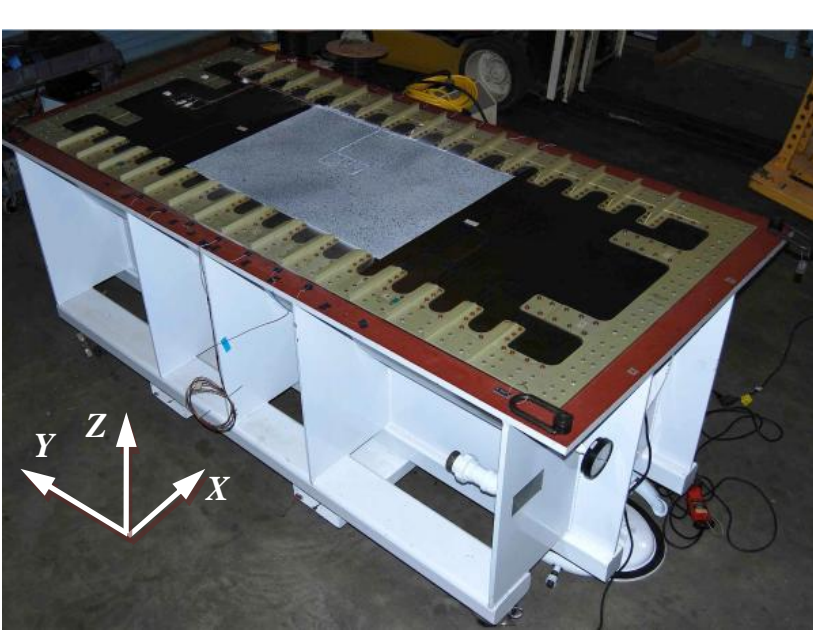

Figure 16. Test set up of the pristine pressure panel. $^{7}$

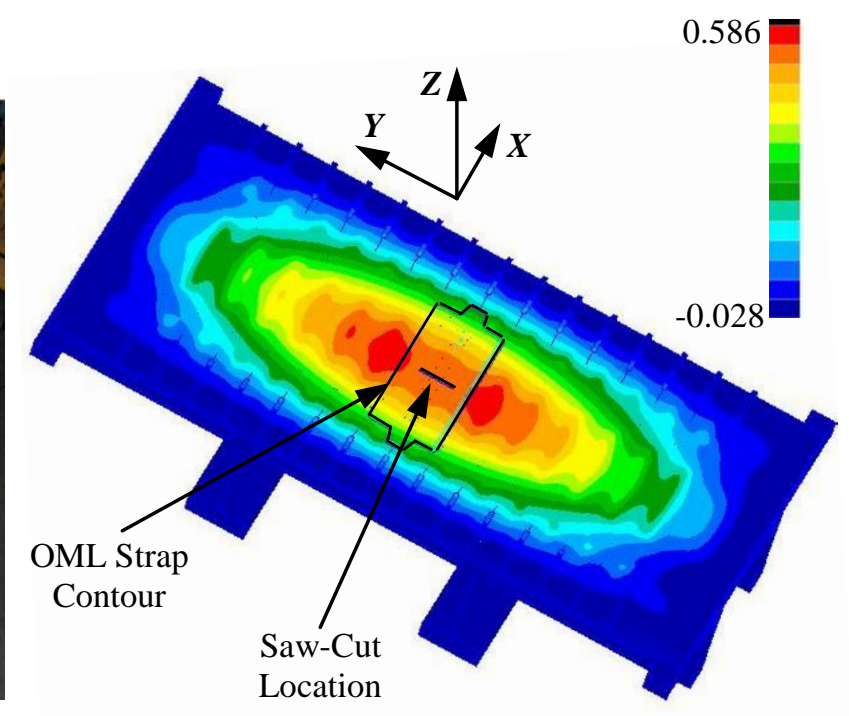

Figure 17. Repaired pressure panel out-of-plane displacement (in.) under ultimate loading of 18.4 psi.

Maximum and minimum principal strain fields of the panel obtained at the ultimate loading level of 18.4 psi are presented in Figure 18 and Figure 19, respectively (repair assembly not shown). For a pressure loading scenario both maximum and minimum principal strain fields are presented because the two are yielding comparable strain levels, while in the previously considered tension loading case, the tension axial strain was clearly dominant. A close-up of a corner section of the panel away from the saw-cut is shown in Figure 18 because the maximum principal strain occurs in this region at the intersection of a stringer and a frame. Both figures also include a closeup section of the panel over which the repair assembly is installed. It is seen in the close-up of Figure 19 that the minimum principal strain occurs where the tapered section of the damaged stringer terminates at the flange. Overall, it is seen in Figure 18 that the maximum principal strain level is $3790 \mu \varepsilon$ and the minimum principal strain in Figure 19 is $-5270 \mu \varepsilon$, both well within allowable values per Table 1 .

Maximum and minimum principal stress fields in the IML repair assembly at the ultimate loading $+10 \%$ level of 20.24 psi are presented in Figure 20 and Figure 21, respectively. It is seen that the repair assembly does not exceed the yielding stress level of $69 \mathrm{ksi}$, therefore remains in the elastic regime. The maximum principal stress levels in the IML pieces are found to be $61.9 \mathrm{ksi}$ and are located in the vicinity of the end fasteners, as seen in Figure 20. The minimum principal stress levels are found to be $-63.6 \mathrm{ksi}$ and are located close the ends of the IML pieces in fillet areas between the flange and web sections of the repair pieces, as seen in Figure 21. The maximum principal stress levels in the OML strap at the ultimate loading $+10 \%$ level of 20.24 psi are presented in Figure 22. 
Very modest maximum stress levels of $18.2 \mathrm{ksi}$ are identified in the area where the fourth and fifth rows of the center flange fasteners are installed (when counting them from the saw-cut location). The minimum principal stress levels in the OML strap were found even less significant when compared with the maximum principal stress levels, and for brevity are not presented.

Finally, the bearing stress distribution due to the fasteners installed in the center panel flange is presented in Figure 23 at the ultimate loading $+10 \%$ level of 20.24 psi. As expected, the center flange again produced the highest bearing stress levels as was the case for the repaired tension panel. The maximum bearing stress of $21.7 \mathrm{ksi}$ is identified at the sixth row of fasteners when counting from the saw-cut location. This value represents less than $22 \%$ of the maximum bearing stress identified for the tension panel. While the bypass strain level distribution at the ultimate load level $+10 \%$ is not explicitly presented for brevity, the overall strain levels in the center flange are also significantly lower when compared to the repaired tension panel. The principal strain levels at a slightly lower loading of 18.4 psi shown in Figures 18 and 19 can be regarded as an indirect but corroborating evidence for the above statement. Therefore, a plot of bearing stress versus bypass strain is also omitted for brevity, as it is certain that its envelope would be contained within the envelope produced based on the tension panel analysis.

In summary, the design adopted from the tension panel repair is sufficient to support the pressurized panel repair and, overall, achieves this objective with larger margins of safety. Therefore, analysis of the repaired pressure panel does not indicate a need to revise the design tailored to the tension loading condition.

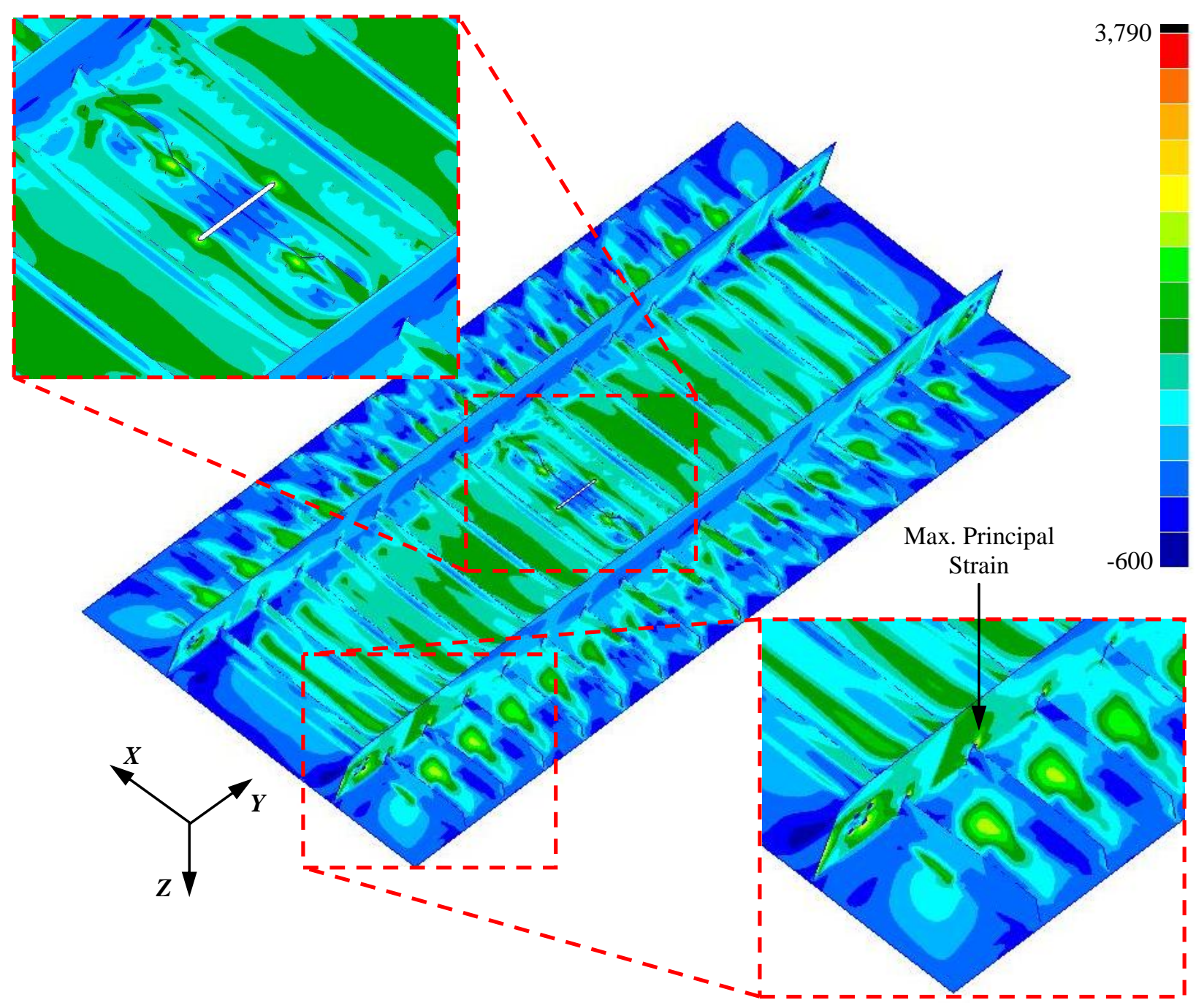

Figure 18. Maximum principal strain $(\mu \varepsilon)$ under ultimate loading of $18.4 \mathrm{psi}$. 

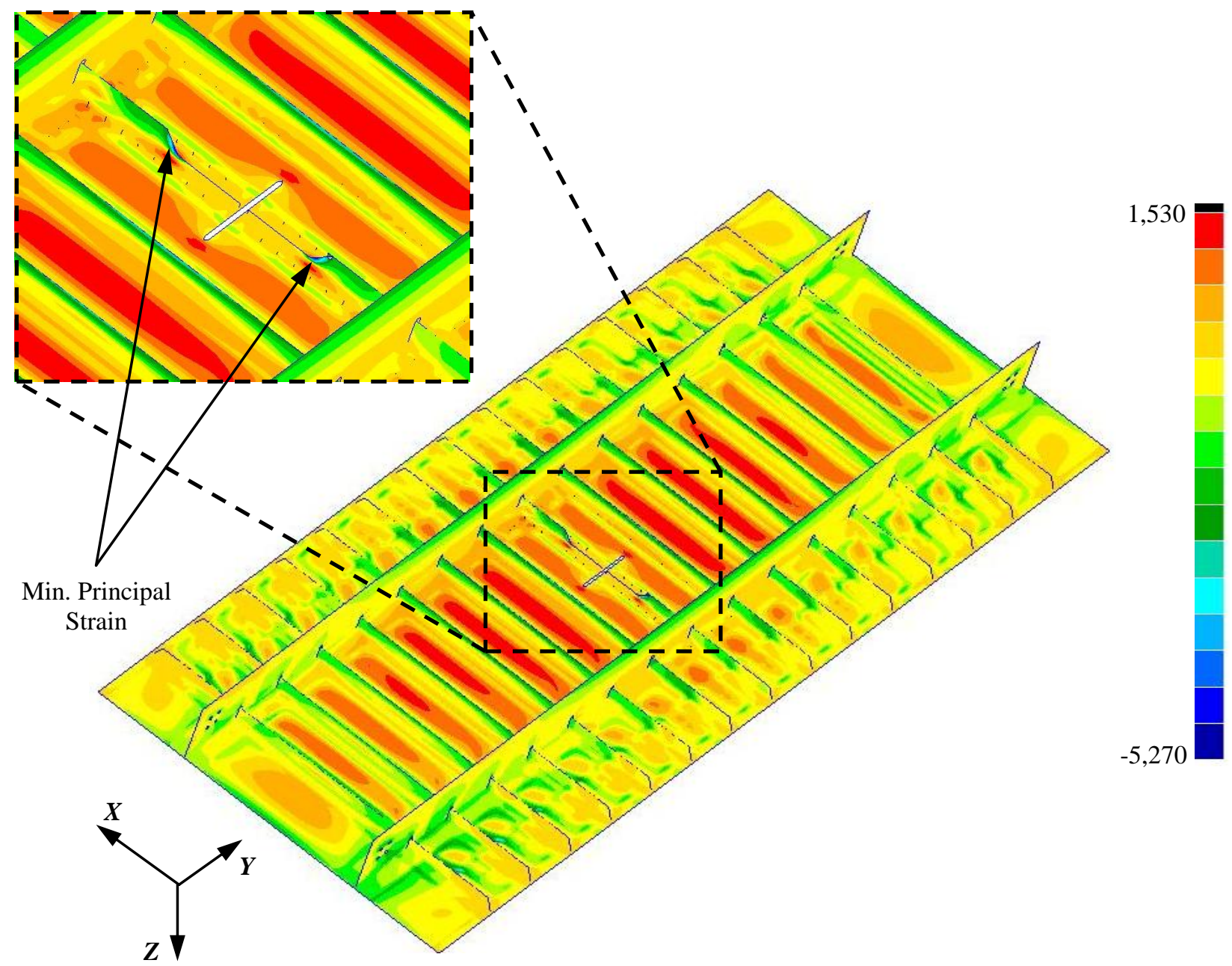

Figure 19. Minimum principal strain $(\mu \varepsilon)$ under ultimate loading of $18.4 \mathrm{psi}$.

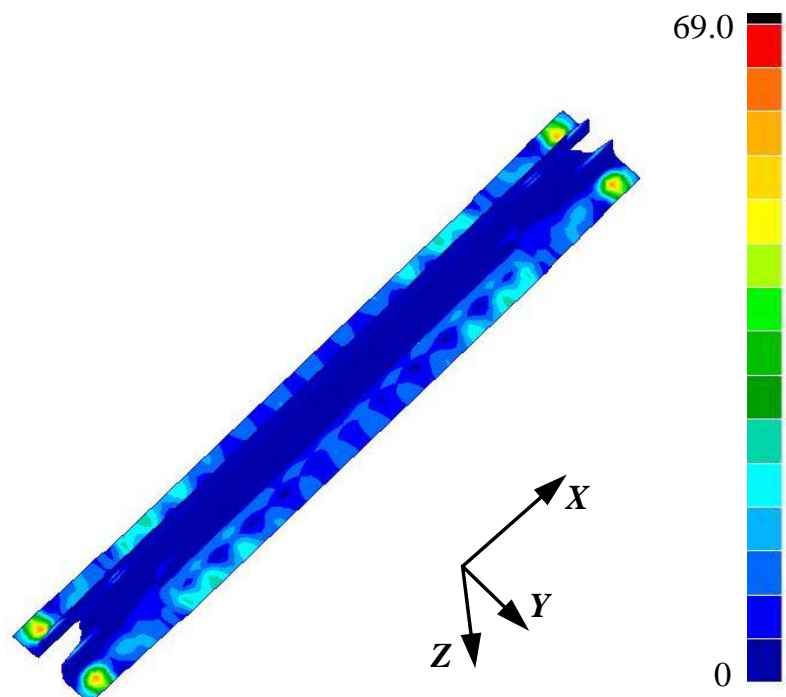

Figure 20. IML repair assembly maximum principal stress (ksi) at ultimate $+10 \%$ loading of 20.24 psi.

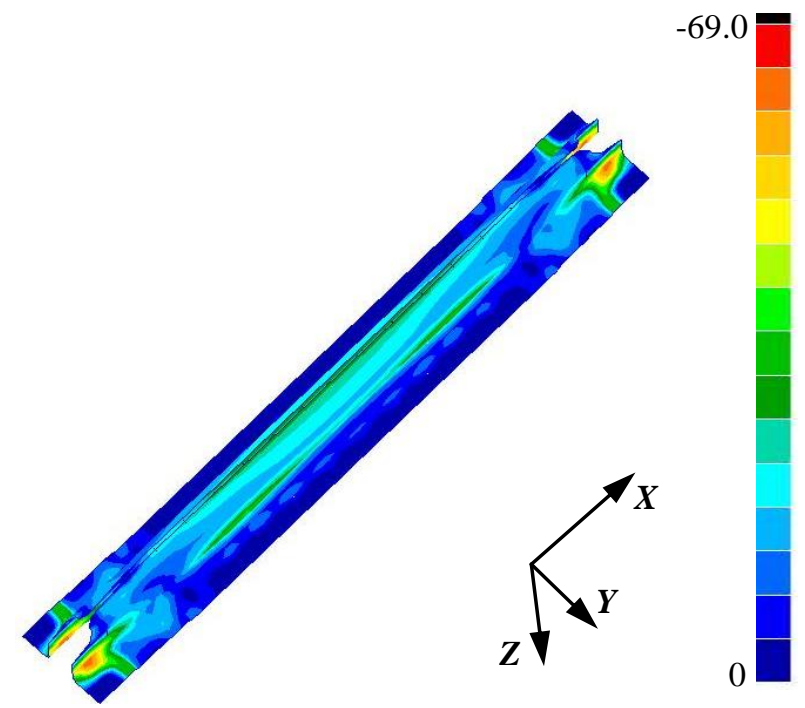

Figure 21. IML repair assembly minimum principal stress (ksi) at ultimate $+10 \%$ loading of 20.24 psi. 


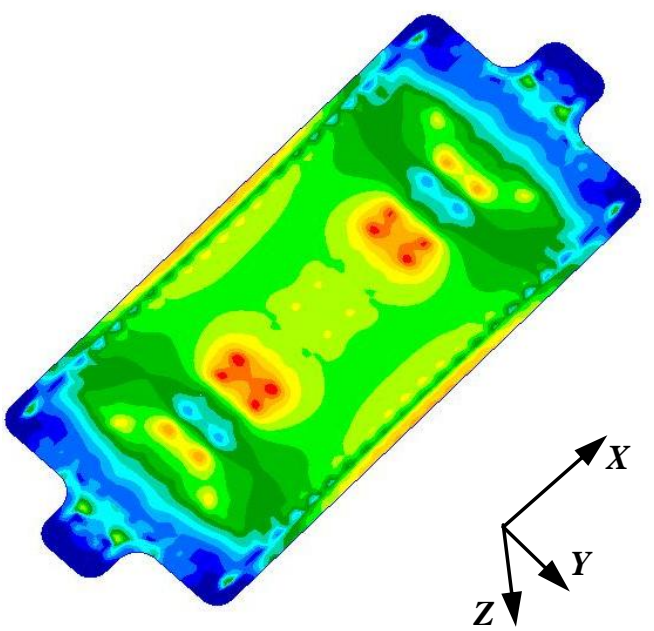

Figure 22. OML strap maximum principal stress (ksi) at ultimate $+10 \%$ loading of 20.24 psi.

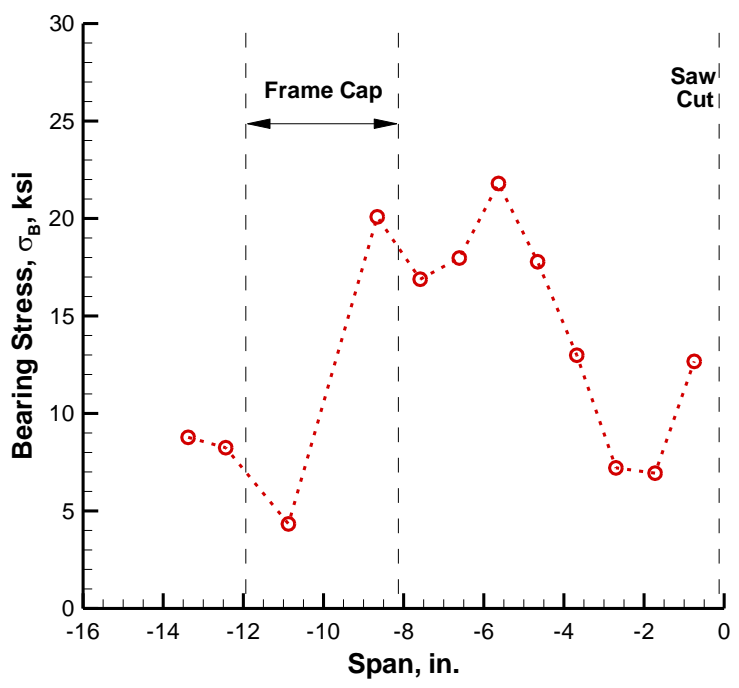

Figure 23. Center flange bearing stress distribution at ultimate $+10 \%$ loading of 20.24 psi.

\section{Concluding Remarks}

Applicability of metallic repairs to panels fabricated using the PRSEUS concept and containing severe but localized damage was considered. The design effort was based on tension loading requirements. While a successful design was found feasible, it also presented challenges, largely stemming from the fact that repair requirements, in general, were not considered in the pristine panel design. Furthermore, a metallic repair was imposed as an additional constraint in this study because of its ease of application in the current operational environment. This restriction further complicated the design, as it may be perceived as an effort to apply a less efficient structural concept to restore full functionality of a more advanced and efficient structure that suffered severe damage.

The successful metallic repair design was achieved by tailoring not only the sizing of the main repair assembly components, but also by refinements of its bolted joints and specific preparation of the damaged panel. The above steps, in general, were intended for the repaired panel to resemble the pristine panel load paths and stiffness as closely as possible, while still requiring the overall design to be easily manufacturable and simple to install.

Once the design based on the tension loading panel was frozen, its robustness was verified for a pressure loading scenario, where panel bending becomes more significant. Overall, larger design safety margins were found under the pressure loading, consistent with the initial assumption to focus the design effort on the tension loading. Both tension and pressure loading configurations are intended for testing to validate the FE analysis approach and tune it, if needed. While certification requirements include also combined loading conditions (e.g. pressure and tension), the current study was limited to individual loading conditions because these are currently available for validation testing. Analysis, possible redesign and validation testing under combined loading conditions should be considered in future work related to repair concepts.

The study utilized advanced FE modeling techniques, such as the use of compliant fasteners defined using connector elements with a node-independent placement in the model. Geometrically nonlinear analysis runs were utilized and the metallic repair assembly accounted for a nonlinear elastic-plastic material behavior. In the tension panel analysis small sections of the repair assembly exceeded the yielding stress when the repaired panel was loaded above the limit loading level. However, panel deformation remained dominated by the in-plane displacement, i.e., no significant geometrically nonlinear behavior was triggered. The opposite was found for the pressure panel where appreciable stiffening due to geometric nonlinearity was identified stemming from larger out-of-plane displacement causing significant in-plane stretching. In this case, however, the yielding stress was never reached in the repair assembly. Note that accounting for material and geometric nonlinearity in the analysis supporting the design effort often leads to a leaner, more efficient design, as plasticity introduces stress relaxation and geometric nonlinearity also suppresses stress levels. In the present effort application of linear analysis yields over-conservative design. 


\section{Acknowledgments}

The author wishes to thank Dawn Jegley and Andrew Lovejoy of NASA Langley Research Center, Structural Mechanics and Concepts Branch, Hampton, VA and George Mills, Kim Linton and Alex Velicki of The Boeing Company, Boeing Research and Technology, Huntington Beach, CA for their helpful discussions during the course of this work.

\section{References}

${ }^{1} \mathrm{Li}$, V. and Velicki, A., "Advanced PRSEUS Structural Concept Design and Optimization," Proceedings of the 12th AIAA/ISSMO Multidisciplinary Analysis and Optimization Conference, AIAA-2008-5840, Victoria, BC, Canada, 2008.

${ }^{2}$ Jegley, D. C., Velicki, A., and Hansen, D. A., "Structural Efficiency of Stitched Rod-Stiffened Composite Panels with Stiffener Crippling," Proceedings of the 49th AIAA/ASME/ASCE/AHS/ASC Structures, Structural Dynamics and Materials Conference, AIAA-2008-2170, Schaumburg, IL, 2008.

${ }^{3}$ Velicki, A., Thrash, P., and Jegley, D. C., "Airframe Development for the Hybrid Wing Body Aircraft," Proceedings of the 47th AIAA Aerospace Sciences Meeting Including The New Horizons Forum and Aerospace Exposition, AIAA-2009-932, Orlando, FL, 2009.

${ }^{4}$ Yovanof, N. P., Velicki A., and Li, V., "Advanced Structural Stability Analysis of a Nonlinear BWB-Shaped Vehicle," Proceedings of the 50th AIAA/ASME/ASCE/AHS/ASC Structures, Structural Dynamics and Materials Conference, AIAA-2009-2452, Palm Springs, CA, 2009.

${ }^{5}$ Velicki, A. and Thrash, P., "Advanced Structural Concept Development Using Stitched Composites," Proceedings of the 49th AIAA/ASME/ASCE/AHS/ASC Structures, Structural Dynamics and Materials Conference, AIAA-2008-2329, Schaumburg, IL, 2008.

${ }^{6}$ Velicki, A., "Damage Arresting Composites for Shaped Vehicles, Phase I Final Report," NASA CR-2009-215932, NASA Langley Research Center, Hampton, VA, September 2009.

${ }^{7}$ Lovejoy, A. E., Rouse, M., Linton, K. A., and Li, V.P., "Pressure Testing of a Minimum Gauge PRSEUS Panel," Proceedings of the 52nd AIAA/ASME/ASCE/AHS/ASC Structures, Structural Dynamics and Materials Conference, AIAA-2011-1813, Denver, CO, 2011.

${ }^{8}$ Velicki, A., Yovanof, N., Baraja, J., Linton, K., Li, V., Hawley, A., Thrash, P., DeCoux, S., and Pickell, R., "Damage Arresting Composites for Shaped Vehicles - Phase II Final Report," NASA CR-2011-216880, NASA Langley Research Center, Hampton, VA, January 2011.

${ }^{9}$ Composite Aircraft Structure, Advisory Circular AC No. 20-107B, U.S. Department of Transportation, Federal Aviation Administration, August 2010.

${ }^{10}$ Przekop, A., "Design and Analysis of a Stiffened Composite Structure Repair Concept," Proceedings of the 52nd AIAA/ASME/ASCE/AHS/ASC Structures, Structural Dynamics and Materials Conference, AIAA-2011-1912, Denver, CO, 2011.

${ }^{11}$ Mirsamadi, S., “Advanced Subsonic Technology (AST) Composite Wing Material Stiffness and Allowable Strength Properties for Stitched Composite Laminates," Report Number 98K0318 (proprietary), The Boeing Company, Advanced Transport Aircraft Development, Long Beach, CA, September 1998.

${ }^{12}$ Title 14 Code of Federal Regulation, Part 25 "Airworthiness Standards: Transport Category Airplanes," Subpart C "Structure," §25.305, Electronic Code of Federal Regulations, http://ecfr.gpoaccess.gov

${ }^{13}$ ABAQUS version 6.11 On-line Documentation, ABAQUS Analysis User's Manual, Dassault Systemes Simulia Corp., Providence, RI, 2011.

${ }^{14}$ MD/MSC Nastran 2010 Quick Reference Guide, MSC Software Corporation, Santa Ana, CA, 2010.

${ }^{15}$ http://www.esrd.com/Products/StressCheckSoftware.aspx 